\title{
Space and Time Study of the Chinese Landscape Painting
}

\author{
Mei Ming ${ }^{1, a}$ \\ ${ }^{1}$ Hankou University, Wuhan 430073,China \\ amingmei@126.com
}

Keywords: landscape painting, space, time

Abstract. The uniqueness of space and time of Chinese landscape painting is build up according to the painter's own consciousness, and in accordance with the sense of mind with the nature of universe, is I blend of time space view, but it is also the freedom of the soul. The space of Chinese landscape painting is presented through physical space, position, three far, inner space; time is presented through the movement of the ink and the change of ink rhythm. "Time" and "space" connect with each other. There is neither the space without time, nor the time wihtout the space. By the analysis of the "time" and "space" of the painting, it shows the landscape painting regulation and art value, and improves the level of painting techniques with in-depth understanding.

\section{The construction and form of the Chinese landscape painting}

The composition and form of landscape painting is closely related to the vitality of landscape painting, at the same time is the author's idea, conception, accomplishment, emotion and etc. in the direct embodiment in the picture. Under the leading of "nature and humanity" ideology, Chinese painters look scenery as "everything is ready for me”. Natural objects in their eyes are full of boundless vitality. It also makes the composition of Chinese traditional landscape painting with romanticism. It broke the limit of space and time. It adopts a kind of "small to the observatory" and "things went on" and "free-way combination" thinking on the composition of a picture. Chinese painters pursue "things and me together" in the creative, and pay attention to the subjective consciousness and the true feelings. This unique form of expression and aesthetic pursuit reflected the typical ethnic style. In traditional Chinese painting, the composition is also referred to as the layout, composition or management position. It is called the "important point in the painting" by the tang dynasty Zhang Yanyuan. Composition of Chinese traditional landscape painting is very exquisite conception of scene, paying attention to the use of opening and closing, both the two sides, the actual condition, and simplified, jagged, such as the law of unity of opposites, in order to achieve "take its mass, nearly far take its potential” artistic effect, and clever images of the blank layout, make the place without drawing into scenic spots.

Composition of Chinese traditional landscape painting is not subjected to the constraints of objective image, but it is a kind of convenient configuration and restructuring, is the integration of visual experience, focuses on performance of the essential characteristics of the object, uses the way of thinking as a kind of image. Thus, the composition and the artist's conception are closely related to the natural and built environment, and the built environment is between the conception and composition of a picture, built environment needs subjective art processing not 
out of the natural landscape reality and on the basis of the natural. Form aesthetic feeling of Chinese landscape painting represents the artist's aesthetic tendency, contains strong subjective feelings, it is a compound of painter rational thinking and subjective mood. Chinese painters prefer to pursue variety in unity, make pictures and abound change the visual style of harmony. In the landscape painting, the combination and penetration of line constitutes the main factor to express the beauty of images. Landscape painters use the aesthetic consciousness through the build level space in the two-dimensional plane, natural object reintegration into the form of rich rhythm, color and decoration, thus forming the composition of Chinese landscape painting unique style and artistic visual language expression. Ingenious combination should be diverse and not mixed and disorderly, pure and not poor. Whether the combination of single or multiple form, the dotted line on the transverse and longitudinal extension cannot have too much repetition, can appear otherwise flexors, not pure, and modeling concise form and do not let a person feel a single.

\section{Space and time of the Chinese landscape painting}

The objective world is the organic unity of time and space as a whole. Everything is exited in a certain time and space. There is neither the space without time, nor the time wihtout the space. Since ancient times, China emphasizes on "favorable climate, geographical and human conditions”. The Chinese landscape painting pays more attention to the main function of the people, people's subjective initiative. Before painting, the painters need to list the natural landscape in the chest. Do have answers, and can't wait to passionately to painting: painting from a tree, mountain, then fully mobilize and play its aesthetic temperament and interest, bolt. "To paint the landscape through deep inside the heart" shows the painter and the integration of real landscape space and time the heart of the landscape. As it is said in the Shi Tao Painting Ana that mountains and rivers also make for the generation of mountains and rivers. Mountains and rivers are based on your painting, and your painting is also based on mountains and rivers. Searching all the different mountains as a rough draft, then mountains and rivers meet with you to make a god and trace and after all become a great painting." I pursue the real myself and of heaven. And the nature of the process, is a kind of spiritual realism of the space, rather than the real reappearance of natural space. This is the concept of space-time in Chinese landscape painting thing I blend.

In "things and I connected together" concept, things represents the objective law close contact with nature, the i represents subjectivity, spiritual experience, subjective expression. "Things" and "I" are unique to China, cleverly contained in traditional Chinese painting of "space" and "time".

\subsection{Space}

(1) Material space. It is a form of "things", namely the object shape in the "six methods". When painting, painting can't deviate from the real, the landscape in the painting does not show the individual characteristics of a specific object such as heaped-up mountains, rocky mountain, the various point of leaves. It only shows certain common features of object put people's perceptions of the material - "class", essence embodied in the picture. The Chinese landscape painting needs to make the image of "class" consistent with objective reality, the dimensional feeling of material itself. 
(2) Position space

Position space is also an expression of the "things", namely "arrangement, before and after the configuration, the size of the jagged, light and shade of the foil in the picture”. All things are common connected with each other; everything cannot exist in isolation, but as a factor in the system or the system. This is to grasp space from the overall relationship. Mountains are growing between the heaven and earth, the water is flowing in the mountain stream cleft, the trees are attached to the landscape, and people's activities are in the nature. The performance of the space cannot out of the feature of material space of things themselves, can't out of the connection between things one by one position space, they are all things, the traditional Chinese painting and painting must abide by the law.

(3) Three far space.

Guo Xi put forward that the three far: high, profound, and flat in the Linquan Gaozhi is also a smart way of landscape space building, which has significant contribution to the Chinese painting. "three far" in a nutshell is what under the peak look for visual effect, givea a person a kind of unattainable, the dimensional feeling of stunning.

(4) The heart space.

In the generation of Chinese landscape painting creation, various artistic image and image spatial location combination is the pursuit of the movement regulation of "one Yin and one Yang”, such as size, black and white, the actual condition and the density, soft, compete, and many contradictions etc. These opposites walk in the paintings alternately through the use of pen and ink, pouring mood of the artist feeling into the painting. Also it makes the people appreciating the painting immersed in it. Emotion expressing in natural phenomena, forms the space above mind "I".

\subsection{Time}

From the kind of paintings, the landscape painting is a concept of time: one part is subject to the facts of the historical development, connected with the character of the historical hero. From the point of view to focuses, its characters are always one of the focus of the painting, is the focus of the vision; the other part is that the landscape painting has the characteristic of nature time (or physical time) in the process of their development through the natural imitation and sublimation; the deepest part is that the landscape painters make their art level unceasingly improved and their mind sublimation, eventually reach outside nature, source state in the heart through their own efforts, which is the nature and humanity level.

Time of landscape painting performance is divided into three categories: natural time (physical), historic time, emotional time (empirical):

(1) The nature of time

Nature time is the basic time to run make world running, it also changes with the running of the earth, generated by the earth's rotation and revolution of the concept of time. Chinese landscape paintings focus on the physical changes taken by the time movement, it developed along with the whole of the ancient Chinese consciousness of philosophy. That is the way the like into the grounds, is also the principle of freehand brushwork in Chinese art. Spring growth, summer long, autumn gathering, winter collecting, these four seasons are most close with people, and is also the biggest change timing problem. Of course, some paintings still describe timeliness and the subject matter of wind and rain or shine, day and night. But the landscape paintings mainly concentrated in the four seasons in the category of the time. Typical 
timeliness works are forest scenery in the slight cold, sunny mountain temple of Li Cheng, and early spring and spring snow in the frontier juncture of Guo Xi, summer mountain and slowly sunset of $\mathrm{Fu}$ Baoshi and so on.

(2)The historic time

Shi Tao said: "pen and ink go over time”. The HeYuan marriage of Sun Benshan shows that the custom of people in Shanbei along the Yellow River marry a woman, brings the viewer into the state of a simple and attractive. The whole picture is a picture of a panoramic landscape, big, bold mountains have a sharp contrast with a team of married women, making even the thick smoke haze penetrate into a kind of strange.

Different area of life is fully in the painting. Artistic language is rich in the picture, so that the work has a very unique appeal making viewers standing in front of the stage as if to marry a woman with a particular moment of joy.

(3)The emotional time (empirical)

Wang Wei said in Syria's painting that "watching the autumn cloud, flying along the sky; feeling the spring breeze with mighty thoughts." That means the artist reach in the artistic creation I belong to a experience through the observation of the natural and feelings and thinking. Artist can only summarize the presenting of time in his arts in the process of accumulating time experience during his life, some are emotional experience in time, some are a plenty of time experience. Works including these two kinds of time, its are immanent is through the artist's mind. The forest of mother Meng of Zhang Ding is a different feeling. The main body of the picture is composed of four tall cypress and a door of the temple. Leaves of the cypress are numerous with a sense of lush. This work constitutes history feeling through the old temple and the gate pale cypress. In a brilliant light, produced a dizziness to people to enter vertigo and difficult to extricate themselves. Hui Wa said when she evaluating this work: in front of this work, I forgot where I am, which year is and whom I am, only feel in the sight of a big piece of green, revitalized, depressed eyeful of cadence, rhythm, strength of folding, full of powerful disappears, it is the soul of the universe unique vision in wisdom.

\section{The function of space and time of the Chinese landscape painting}

The performance time can get well internal relation between the object together, so it can obtain the integral effect of the harmony and unity. Unique time representative object plays a bigger role in showing and refining the topics. Painter draws based on the historical determinism and life word repeatedly performance and pioneering, the inner of which is the return of the meaning of life, and highlights the value of its own body through the history of this natural physical time and return.

Li Keran said that artistic conception is both the concentrated reflection of part and the essence of the objective things, and it is also the embodiment of the author in his passions. Every screech and paint is not only the performance objective image, but also the express their feelings. Painters build a scene in the works to show that Chinese landscape painting artistic conception is to pursue its inherent meaning, to pursue immutability. Performance by the continuation of life and return is "immortal", namely the circle of life and the eternal existence. So, with the help of a good object and way, the performance of the time will create a empty asked belongs to historical or natural landscape, this space has a number of layers of depth with continuity and immutability. 
Time and space in the Chinese landscape painting is not only a performance of objective image, more importantly, it expresses the author's feelings, thoughts according to the painter's own consciousness and their connection, feeling and creation with the nature and the universe, which build up a bigger space with the freedom of their soul. It can also show the author's own accomplishment and understanding.

Landscape painting advocates "searching all unique mountains for drafts”, and performing self-consciousness on the basis of following the natural. Therefore, Chinese painting also has the saying that the quality of the painter is also the quality of the painting. Different people's picture shows different flavor, elegant, urban, stupid, childlike, domineering and etc. Chinese landscape painting also cultivates painters' morality and quality, to improve the quality and cultural of the artist, which is the real treasure of art.

Through the analysis and understand of the time and space of Chinese landscape painting, not only can improve our comprehension of "six methods, but also can improve the understanding of painting techniques on thought. Painting things like the real things reflects the material space, "operating space” manifests the location space, "lively" expresses spiritual space, "old ancient method", "transfer modification" and improving the movement of pen and ink techniques are closely related the performance time.

\section{Summary}

Time like acoustic infinite, space as infinite county in the mountains. In the landscape picture, the visual line over the limit of reality, and freedom into the depth of the soul. Space is the composition of the picture, is my space; time is the movement of ink, rhythm changes. The movement regulation of Yin and Yang of time is in dominant, and shows the space. The exist of time is on the premise of the existence of space, then space finally exists. There is neither the space without time, nor the time wihtout the space. Both depend on each other, cannot exist separately.

\section{References}

[1] Huang Qiang, Art sprits of the traditional ten countries[J], Art Village, 2003(11):100-103.

[2]Chen Chiyu, The art compare of characteristics of the traditional landscape painting[J], Hundred Schools in arts, 2006,27(2): 84-87.

[3 ] Yang Danian, Paintings of all the Chinese painters in different dynasty[J], Jiangsu education publishing house,2005,10(1):238-224.

[4] Fu Baoshi, The theory of Chinese painting[M], Jiangsu education publishing house,2005,10.

[5] Zhong Jiaji, New theory of the washing painting, People's art publishing house,2002. 